\title{
Esophagus and Esophagogastric Junction Cancer pN2 TNM Finding v7
}

National Cancer Institute

\section{Source}

National Cancer Institute. Esophagus and Esophagogastric Junction Cancer pN2 TNM

Finding v7. NCI Thesaurus. Code C89741.

Esophagus and esophag og astric junction cancer with metastasis in 3-6 regional lymph nodes. (from AJCC 7th Ed.) 